\title{
Improvements in clinical response between 12 and 24 weeks in patients with rheumatoid arthritis on etanercept therapy with or without methotrexate
}

\author{
A Kavanaugh, ${ }^{1}$ L Klareskog, ${ }^{2}$ D van der Heijde, ${ }^{3} \mathrm{~J} \mathrm{Li,}{ }^{4}$ B Freundlich, ${ }^{5}$ M Hooper ${ }^{4}$
}

${ }^{1}$ Center for Innovative Therapy, Division of Rheumatology, Allergy, Immunology, UCSD, San Diego, California, USA;

${ }^{2}$ Rheumatology Unit,

Department of Medicine, Karolinska Institutet, Stockholm,

Sweden; ${ }^{3}$ Department of Rheumatology, Leiden University Medical Center, Leiden, The Netherlands; ${ }^{4}$ Amgen Inc, Thousand Oaks, California, USA; ${ }^{5}$ Wyeth Pharmaceuticals, Collegeville, Pennsylvania, USA

Correspondence to: Dr A Kavanaugh, Center for Innovative Therapy, Division of Rheumatology, Allergy, and Immunology, 9500 Gilman Drive, Mail Code 0943, La Jolla, CA 92093, USA:

akavanaugh@ucsd.edu

Accepted 9 May 2008 Published Online First 5 June 2008

This paper is freely available online under the BMJ Journals unlocked scheme, see http:// ard.bmj.com/info/unlocked.dtl

\section{ABSTRACT}

Background: Whereas many patients respond quickly to treatment with tumour necrosis factor (TNF) inhibitors, some patients may experience significant but delayed responses.

Objective: To evaluate the clinical response between 12 and 24 weeks in subjects with rheumatoid arthritis from the Trial of Etanercept and Methotrexate with Radiographic Patient Outcomes.

Methods: Clinical response was assessed at 24 weeks in 12-week non-responders, according to American College of Rheumatology (ACR) response criteria. The proportion of subjects who successfully maintained response to 52 weeks was analysed, as were radiographic outcomes.

Results: Data from 682 subjects were included in the analysis. Non and partial responders in all three groups (etanercept, methotrexate and etanercept plus methotrexate) at week 12 showed an improvement in responses at week 24 . Over $80 \%$ of the week 24 ACR20/ $50 / 70$ responders in the etanercept plus methotrexate arm sustained their response to 52 weeks. In the etanercept arms, a delayed clinical response was not associated with increased radiographic progression at week 52.

Conclusion: A significant proportion of non and partial responders to etanercept with or without methotrexate therapy at week 12 achieved a good clinical response or improved their overall clinical response at week 24 . Discontinuing TNF inhibitor therapy at 12 weeks may be premature in some rheumatoid arthritis patients.

Tumour necrosis factor (TNF) inhibitors, particularly in combination with methotrexate, have demonstrated excellent symptomatic and radiographic control in rheumatoid arthritis. ${ }^{12}$ A rapid clinical response to such therapy, often within 2 weeks, is commonly observed. ${ }^{134}$ It is widely held that most patients who respond to TNF inhibitor therapy will show an adequate response after 12 weeks of treatment. Given the cost and possible unnecessary exposure to an ineffective medication, 12 weeks has been suggested as a timepoint at which TNF inhibitor therapy should be discontinued in non-responders. Discontinuing therapy may be premature, however, if a proportion of non-responders at 12 weeks become responders at later timepoints. ${ }^{5} 6$

In this analysis, we used data from the Trial of Etanercept and Methotrexate with Radiographic Patient Outcomes (TEMPO) to evaluate the extent to which subjects not responding to TNF inhibitor therapy at 12 weeks might respond at 24 weeks.
The long-term sustainability of the improvement in response and radiographic outcome at week 52 was also assessed.

\section{SUBJECTS AND METHODS Subjects}

Data from subjects treated with etanercept, methotrexate and etanercept plus methotrexate from the TEMPO study were used in this analysis. ${ }^{1}$ Briefly, subjects had disease duration of between 6 months and 20 years, had active rheumatoid arthritis defined as 10 or more swollen and 12 or more painful joints and had at least one of the following: erythrocyte sedimentation rate $28 \mathrm{~mm} /$ h or greater; C-reactive protein $20 \mathrm{mg} / \mathrm{l}$ or greater; or morning stiffness for 45 minutes or more. Etanercept was given as $25 \mathrm{mg}$ twice a week. Patients randomly assigned to methotrexate arms received $7.5 \mathrm{mg}$ methotrexate once a week, which was escalated to $20 \mathrm{mg}$ once a week over 8 weeks.

\section{Evaluations}

American College of Rheumatology (ACR)20/50/ 70 responses and Disease Activity Score using 28 joints (DAS28) were assessed at weeks 12, 24 and 52. Based on their clinical response at week 12 , subjects were categorised into ACR20 non-responders (no response at week 12), ACR50 nonresponders (ACR20 responders, but not ACR50 responders) and ACR70 non-responders (ACR50 responders, but not ACR70 responders).

Among the subjects who showed an improvement in clinical response at week 24 , the proportion of subjects who successfully maintained the improvement to at least 52 weeks was assessed. The radiographic outcome at week 52 was evaluated using the mean change in total Sharp score (TSS) and the percentage of non-progressors (TSS change $\leq 0$ ).

Frequencies and percentages were provided for improvement and decrease in ACR response and disease activity scores. One-way analysis of variance was used to test the difference in DAS28 scores among groups (non-responder to nonresponder, non-responder to responder and responder to responder). The paired-sample $t$ test was used to examine the difference in DAS28 scores between week 12 and week 24 and for week 12 European League Against Rheumatism (EULAR) non-responders who responded at week 24. Fisher's exact test was used to compare the difference in radiographic progression between the week 12 responders and week 12 non-responders who became responders at week 24 within each treat- 
Figure 1 Improvement and sustainability of American College of Rheumatology response.

ACR, American College of Rheumatology; ETN, etanercept; MTX, methotrexate; $\mathrm{N}$, total of subgroup; NR, non-responder; $\mathrm{R}$, responder.
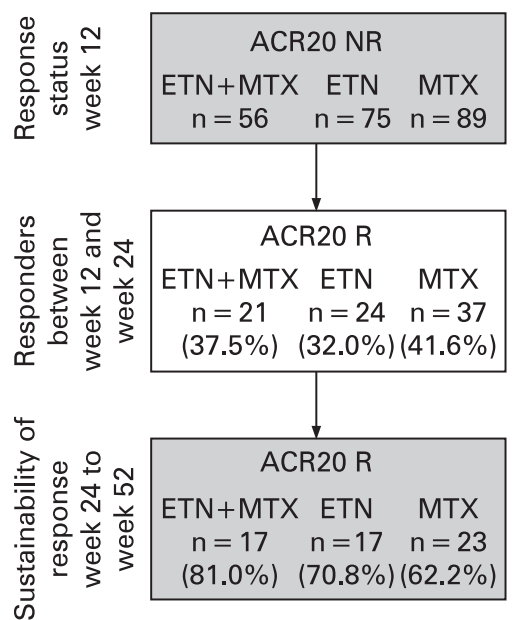

ACR50 R/ACR70 NR

ETN + MTX ETN MTX

$n=45 \quad n=52 \quad n=46$
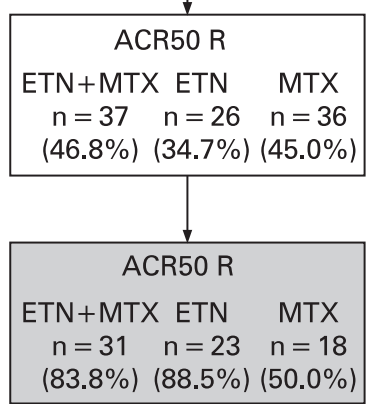

ment group. Bonferroni adjustment was used for multiple comparisons. Logistic regression models were used to identify predictors of response at 12 weeks. Results were considered significant at $p \leqslant 0.05$ two-sided. Non-responder imputation was used to handle missing clinical and radiographic data. All analyses were performed using the SAS STAT system version 9.1.

\section{RESULTS}

\section{Baseline demographics}

The TEMPO trial included 682 subjects (231 in the etanercept plus methotrexate arm, 223 in the etanercept monotherapy arm and 228 in the methotrexate monotherapy arm). Baseline demographic characteristics for TEMPO subjects have been described previously. ${ }^{1}$ Briefly, the mean disease duration was 6.8 years, with $76 \%$ of subjects rheumatoid factor positive. The mean age was 52.5 years and approximately three-quarters were women. Subjects had a mean baseline DAS28 score of 6.8 .

\section{Improvement in ACR response}

Results from the analysis of ACR20/50/70 responses at week 24 in week 12 non and partial responders are shown in fig 1 . In the etanercept plus methotrexate-treated subjects, $37.5 \%$ of week 12 ACR2 0 non-responders became ACR20 responders, $46.8 \%$ of week 12 ACR50 non-responders became ACR50 responders and $51.1 \%$ of week 12 ACR70 non-responders became ACR70 responders. Similar improvements were also observed in the monotherapy arms $(23 \%-35 \%$ in the etanercept monotherapy arm and $41 \%-45 \%$ in the methotrexate monotherapy arm).

\section{Sustainability of ACR response}

Of 21 ACR20, 37 ACR50 and 23 ACR70 responders at week 24 in the etanercept plus methotrexate arm, 17 (81.0\%), 31 (83.8\%) and 19 (82.6\%) subjects, respectively, showed a sustained response at week 52 (fig 1 ). The sustainability of response was more variable in the etanercept and methotrexate monotherapy arms, ranging from $67 \%$ to $89 \%$ and $50 \%$ to $63 \%$, respectively.

A decrease in ACR20/50/70 response was observed in some subjects between weeks 12 and 24 . In the etanercept plus methotrexate arm, 18 out of 175 ACR20 responders (10.3\%), five out of 96 ACR50 responders (5.2\%) and five out of 51 ACR70 responders (9.8\%) decreased their response at week 24 (data not shown). Similarly, $11.5 \%$ of ACR20, 23.3\% of ACR50 and $4.8 \%$ of ACR70 responders in the etanercept monotherapy arm and $16.5 \%$ of ACR20, $10.2 \%$ of ACR50 and $23.1 \%$ of ACR70 responders in the methotrexate monotherapy arm decreased their response between weeks 12 and 24 .

\section{Improvement in DAS28 scores}

In subjects from all three treatment arms who were EULAR (moderate or good) non-responders at week 12, but became responders at week 24, their mean DAS28 scores showed a significant decrease from baseline to week 24 and from week 12 to week $24(p<0.05)$ (fig 2$)$. In the non-responder to nonresponder group, mean DAS28 scores at week 12 were similar to those in the non-responder to responder group, arguing against a "partial response" as the explanation for the later improvement for those patients. Of note, mean DAS28 scores in the 12week non-responders/24-week responders improved significantly at 24 weeks, but not to the same extent as for subjects who achieved a response at 12 weeks.

\section{Radiographic outcome at week 52}

To determine if there was a slowing of radiographic progression in subjects who were ACR20 non-responders at week 12, but became responders at week 24 compared with week 12

Table 1 Radiographic outcome at week 52 in week 12 and week 24 responders

\begin{tabular}{lrlcc}
\hline & N & NP (\%) & p Value & Mean TSS (95\% CI) \\
\hline ETN + MTX week 12 responder & 171 & 69.0 & 0.440 & $-0.53(-0.880$ to -0.185$)$ \\
ETN + MTX week 24 responder & 20 & 80.0 & & $-1.35(-2.472$ to -0.234$)$ \\
ETN week 12 responder & 145 & 59.3 & 0.177 & $-0.23(-0.690$ to 0.216$)$ \\
ETN week 24 responder & 24 & 75.0 & & $-0.19(-1.043$ to 0.662$)$ \\
MTX week 12 responder & 133 & 48.1 & 0.037 & $0.64(0.078$ to 1.202$)$ \\
MTX week 24 responder & 36 & 27.8 & & $2.82(-0.487$ to 6.145$)$ \\
\hline
\end{tabular}

ETN, etanercept; MTX, methotrexate; NP, non-progressor defined by TSS $\leqslant 0$; TSS, total Sharp score. 

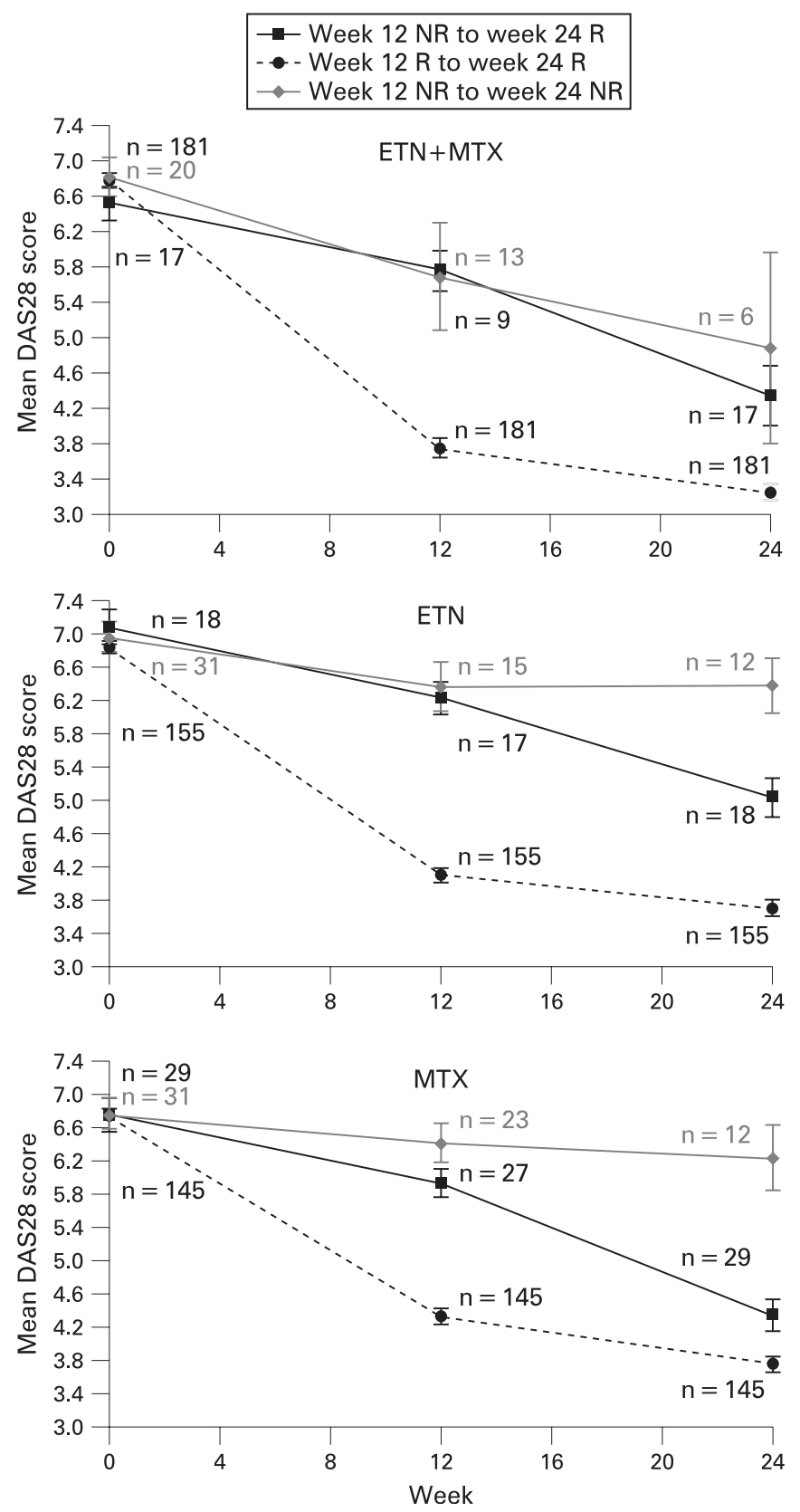

Figure 2 Mean DAS28 scores in EULAR (moderate or good) responders and non-responders.

DAS28, Disease Activity Score using 28 joints; ETN, etanercept; EULAR, European League Against Rheumatism; MTX, methotrexate; N, total of subgroup; NR, non-responder; $R$, responder.

responders, the mean change in TSS and the percentage of nonprogressors were evaluated at week 52 . Results are shown in table 1. No statistically significant difference was observed in the mean TSS or the percentage of non-progressors between the 12 -week versus the 24 -week responders in the etanercept or etanercept plus methotrexate arms. In the methotrexate arm, however, the 24-week responders showed a significant increase in TSS at 52 weeks compared with the 12 -week responders.

\section{Predictors of improvement in response}

No baseline characteristics or week 12 clinical variables (Creactive protein, erythrocyte sedimentation rate, swollen joint count, tender joint count, Health Assessment Questionnaire, visual analogue scale for pain, physician global assessment and DAS28) were significantly associated with a delayed response at 24 weeks.

\section{DISCUSSION}

In this retrospective analysis, a substantial improvement in clinical response was observed between 12 and 24 weeks in subjects with rheumatoid arthritis in all three treatment arms from the TEMPO trial, including those who were non or partial responders at 12 weeks. The improvement in response at 24 weeks was most apparent in the etanercept plus methotrexate arm, in which $37.5 \%$ of ACR $20,46.8 \%$ of ACR 50 and $51.1 \%$ of ACR70 non-responders became ACR20, ACR50 and ACR70 responders, respectively, at week 24 . Similar improvements were observed for DAS28 scores in all three treatment arms.

The delayed response observed at 24 weeks was largely sustained in $80 \%$ of subjects to 52 weeks and was not associated with an inferior outcome with regard to the inhibition of radiographic progression at 52 weeks in the etanercept and etanercept plus methotrexate arms.

There are no clear guidelines on the appropriate treatment trial duration for TNF inhibitors. Recommendations from international guidelines vary, with most indicating 12 weeks as a time to assess response after TNF inhibitor therapy. Whereas some recommend discontinuing therapy at 12 weeks for non-responders, others allow for doctor's discretion on whether or not to continue therapy.-12

Importantly, an analysis of disease variables and patient characteristics failed to identify any predictive factors.

The implications of this assessment are relevant with regard to the subsequent treatment of patients "failing" TNF inhibitor therapy at 12 weeks. It has been shown that patients who have "failed" therapy with a TNF inhibitor have somewhat lesser ACR responses to any second-line biological therapy. ${ }^{13-15}$ Therefore, optimising the first treatment course with a TNF inhibitor could improve primary response rates and result in less switching between biological agents.

Limitations of the current study include the retrospective nature of the analysis. Moreover, these findings are from patients enrolled in a randomised clinical trial who met the specific inclusion criteria and had high disease activity. Therefore, these observations may not reflect patients in a real-world setting.

In conclusion, findings from this retrospective analysis suggest that a significant proportion of patients who do not achieve a clinical response 12 weeks after the initiation of etanercept with or without methotrexate therapy may benefit from continuing therapy for up to 24 weeks. Additional benefits of continuing therapy for up to 24 weeks include the sustainability of the 24-week gain in response through at least one year while maintaining radiographic protection.

Acknowledgements: The authors wish to thank Meera Kodukulla, PhD, for providing assistance in the drafting of this manuscript.

Funding: This study was supported by Immunex Corporation, a wholly owned subsidiary of Amgen Inc, and by Wyeth Pharmaceuticals.

Competing interests: AK has conducted clinical studies funded by Amgen. LK has received research grants and/or served on advisory committees for the following companies: Wyeth, Schering-Plough; Abbott, Roche, Bristol Meyers Squibb, AstraZeneca, Amgen and Centocor. DvdH is a consultant and/or has received research grants from the following companies: Abbott, Amgen, Centocor, Bristol Meyers Squibb, Merck, Wyeth, UCB and Roche. BF is a full-time employee of Wyeth Pharmaceuticals. JL and $\mathrm{MH}$ are full-time employees of Amgen Inc.

Ethics approval: Ethics approval was obtained. 
Contributors: Individual analyses for this study were designed by Amgen and Wyeth Pharmaceuticals. This specific report was designed by Amgen and Wyeth Pharmaceuticals with input from AK, LK and DvdH. Data analyses were run by JL. The authors developed the manuscript with writing assistance from Amgen Inc and made decisions about submission for publication in collaboration with Amgen.

\section{REFERENCES}

1. Klareskog L, van der Heijde D, de Jager JP, et al. Therapeutic effect of the combination of etanercept and methotrexate compared with each treatment alone in patients with rheumatoid arthritis: double-blind randomised controlled trial. Lancet 2004;363:675-81.

2. Van der Heijde D, Klareskog L, Rodriguez-Valverde V, et al. Comparison of etanercept and methotrexate, alone and combined, in the treatment of rheumatoid arthritis: two-year clinical and radiographic results from the TEMPO study, a doubleblind, randomized trial. Arthritis Rheum 2006;54:1063-74.

3. Bathon JM, Martin RW, Fleischmann RM, et al. A comparison of etanercept and methotrexate in patients with early rheumatoid arthritis. N Eng/ J Med 2000;343:1586-93.

4. Weinblatt ME, Kremer JM, Bankhurst AD, et al. A trial of etanercept, a recombinant tumor necrosis factor receptor:Fc fusion protein, in patients with rheumatoid arthritis receiving methotrexate. $N$ Engl J Med 1999;340:253-9.

5. Landewe R, van der Heijde D, Klareskog L, et al. Disconnect between inflammation and joint destruction after treatment with etanercept plus methotrexate. Arthritis Rheum 2006:54:3119-25.

6. Smolen JS, Han C, Bala M, et al. Evidence of radiographic benefit of treatment with infliximab plus methotrexate in rheumatoid arthritis patients who had no clinical improvement: a detailed subanalysis of data from the Anti-Tumor Necrosis Factor
Trial in Rheumatoid Arthritis With Concomitant Therapy study. Arthritis Rheum 2005; 52:1020-30

7. Emery P, Reginster J-Y, Appelboom T, et al. WHO Collaborating Centre consensus meeting on anti-cytokine therapy in rheumatoid arthritis. Rheumatology 2001:40:699-702.

8. Furst DE, Breedveld FC, Kalden JR, et al. Updated consensus statement on biological agents for the treatment of rheumatic diseases, 2006. Ann Rheum Dis 2006;65(Suppl):iii2-15.

9. Konttinen YT, Seitsalo S, Lehto M, Santavirta S. Current management: management of rheumatic diseases in the ra of biological anti-rheumatic drugs. Acta Orthop 2005; 76:614-19.

10. Ledingham J, Deighton C. Update on the British Society for Rheumatology guidelines for prescribing TNFalpha blockers in adults with rheumatoid arthritis (update of previous guidelines of April 2001). Rheumatology 2005;44:157-63.

11. Mok C-C. Consensus statements on the indications and monitoring of anti-tumor necrosis factor (TNF) therapy for rheumatic diseases in Hong Kong. Hong Kong Bull Rheum Dis 2005;5:19-25.

12. Rodriguez-Valverde V, Caliz RC, Alvaro Alvaro-Gracia JM, et al. III Actualizacion del consenso de la Sociedad Espanola de Reumatologia sobre terapia biologica en la artritis reumatoide. Reumatol Clin 2006;2(Supl 2):S52-9.

13. Cohen SB, Emery P, Greenwald MW, et al. Rituximab for rheumatoid arthritis refractory to anti-tumor necrosis factor therapy. Arthritis Rheum 2006;54:2793-806.

14. Genovese MC, Becker J-C, Schiff M, et al. Abatacept for rheumatoid arthritis refractory to tumor necrosis factor alpha inhibition. N Eng/ J Med 2005:353:1114-23.

15. Iannone F, Trotta F, Monteccuco C, et al. Etanercept maintains the clinical benefit achieved by infliximab in patients with rheumatoid arthritis who discontinued infliximab because of side effects. Ann Rheum Dis 2007:66:249-52.

\section{Submit an eletter, and join the debate}

eLetters are a fast and convenient way to register your opinion on topical and contentious medical issues. You can find the "submit a response" link alongside the abstract, full text and PDF versions of all our articles. We aim to publish swiftly, and your comments will be emailed directly to the author of the original article to allow them to respond. eLetters are a great way of participating in important clinical debates, so make sure your voice is heard. 